\title{
ESPAÇOS LIVRES DE USO PÚBLICO NA PREVENÇÃO DO CRIME: UM ESTUDO SOBRE A REGIONAL 3 DE VILA VELHA - ES
}

\author{
ALI, Pâmella Cosme \\ UVU, e-mail: pamella.ali@hotmail.com \\ RAMOS, Larissa Leticia Andara \\ UVV, e-mail: larissa.ramos@uvv.br \\ JESUS, Luciana Aparecida Netto \\ UFES, e-mail: luciana.njesus@gmail.com
}

\begin{abstract}
RESUMO
A qualidade de vida urbana está diretamente ligada ao desenvolvimento da interação social e bem-estar, muitas vezes promovida pelo desenvolvimento de espaços abertos e sua relação com áreas verdes, influenciando diretamente a saúde física e mental de seus usuários. O estudo parte da análise sobre a valorização dos espaços livres de uso público e como esses espaços podem auxiliar na prevenção do crime. Nesse sentido, o objetivo deste trabalho foi realizar o levantamento dos espaços livres de uso público e compreender como esses espaços podem auxiliar na prevenção do crime no município de Vila Velha - ES. Para esse efeito foi considerada exclusivamente a área de corte do Grande Aribiri (Regional 3), a fim de identificar e quantificar essas áreas e sua relação com a cidade. Como resultado, foi possível identificar que apenas $30 \%$ da população de toda Regional é beneficiada com áreas livres de uso público, sendo assim essas áreas não atendem aos bairros da Região de maneira homogênea.
\end{abstract}

Palavras-chave: Espaços livres de uso público, prevenção de crimes.

\begin{abstract}
The quality of urban life is directly linked to the development of social interaction and well-being, often promoted by the development of open spaces and its relation with green areas, directly influencing the physical and mental health of its users. The study starts from the analysis about the valuation of free spaces for public use and how these spaces can help in crime prevention. In this sense, the objective of this work was to survey the free spaces for public use and to understand how these spaces can aid in crime prevention in the municipality of Vila Velha - ES. For this purpose, it was considered exclusively the area of Grande Aribiri (Regional 3), in order to identify and quantify these areas and their relation with the city. As a result, it was possible to identify that only $30 \%$ of the population of the whole Region is benefited with areas free of public use, so these areas do not serve the neighborhoods of the Region homogeneously.
\end{abstract}

Keywords: Free spaces for public use, crime prevention.

\section{INTRODUÇÃO}

As áreas livres de uso público estão gerando cada vez mais interesse no que diz respeito a sua influência em assegurar qualidade de vida no seu entorno.

É importante compreender as diferentes concepções sobre os espaços livres entre os autores e, ainda mais indispensável, é entender esses conceitos que se complementam.

Magnoli (apud Tangari, 2009) define os espaços livres urbanos como todos os espaços livres de edificação: tais como quintais, jardins públicos ou privados,

ALI, P. C.; RAMOS, L. L. A.; JESUS, L. A. N. Espaços livres de uso público na prevenção do crime: um estudo sobre a regional 3 de Vila Velha - ES. In: SIMPÓSIO BRASILEIRO DE QUALIDADE DO PROJETO NO AMBIENTE CONSTRUÍDO, 6., 2019, Uberlândia. Anais... Uberlândia: PPGAU/FAUED/UFU, 2019. p 75-87. DOI https://doi.org/10.14393/sbqp19008. 
ruas, avenidas, praças, parques, rios, florestas, mangues e praias urbanas, ou simples vazios urbanos, ou seja, independente se for um espaço público ou privado. Para Lynch (1960), existe uma contraposição, um paralelo, no que se refere aos espaços abertos e espaços fechados das edificações.

Para Gehl (2014), os espaços livres de uso público, não são apenas áreas para atividades de lazer, áreas recreativas e atividades esportivas, esses espaços quando possuem qualidade física, tais como, mobiliário urbano, qualidade visual, áreas de convívio, proteção e segurança, são capazes de influenciar nas atitudes e atividades de seus usuários ao ar livre, convidando as pessoas não só para caminhar, mas também para participar de uma vida em comunidade, propiciando convívio e encontro, tornando a vida urbana versátil e variável.

Cavalheiro e Del Picchia (1992) conceituam os espaços livres como algo mais abrangente do que somente relacionando-os as áreas verdes, mas os incorpora ao papel ecológico e a prática do lazer ao ar livre. "Os espaços livres desempenham basicamente papel ecológico, no amplo sentido, de integrador de espaços diferentes, baseando-se, tanto no enfoque estético, como ecológico e de oferta de áreas para o desempenho de lazer ao ar livre" (CAVALHEIRO; DEL PICCHIA, 1992 Apud BARGOS; MATIAS, 201 1, p.175).

Diante da concepção de diferentes autores é possível considerar que os espaços livres compreendem os espaços públicos como praças, parques, vias, as orlas e as praias, áreas privadas sem construção e vazios potenciais. Estes por sua vez são superfícies de extrema importância, tanto para equilíbrio ambiental das cidades como para o bem-estar e qualidade de vida dos seus usuários. Segundo Mendonça (2015), os espaços livres de uso público de práticas sociais são aqueles destinados ao lazer, atividades recreativas e esportivas. Fazem parte deste grupo as praças, parques urbanos, espaços residuais associados à malha viária e faixa de areia da praia próxima ao mar.

As praças e os parques urbanos são considerados espaços livres incorporados a malha urbana, tendo como incumbência de incentivar, como já visto, a vida comunitária.

Segundo Carneiro e Mesquita (2000, p.28) parques urbanos, "são espaços livres públicos com função predominante de recreação, ocupando na malha urbana uma área em grau de equivalência superior à da quadra típica urbana". Estes espaços desempenham um papel fundamental para a qualidade de vida das pessoas que usufruem dessas áreas e principalmente com o papel de agentes transformadores de qualificação da paisagem urbana.

Segundo Garcia e Miranda (2014, p. 6) "Os espaços livres públicos estão vinculados à formação e à transformação da imagem urbana, contribuindo para qualificar a paisagem". Faz-se necessário destacar que essa transformação da imagem urbana é atribuída a diretrizes básicas de projeto, que segundo Tângari (2009, apud GARCIA; MIRANDA, 2014, p. 6) são características físicas como: "localização, distribuição, permeabilidade (física e visual) e qualidade paisagística e segundo atributos psicológicos: legibilidade e apropriação por parte da população".

Ressalta-se, nesta perspectiva, as iniciativas públicas e a importância do Estatuto da Cidade, na forma da lei $n^{\circ} 10.257$ de 2001, que traz diretrizes sobre 
Política Urbana, onde seu principal objetivo é que todos os cidadãos tenham acesso às oportunidades que a vida urbana de qualidade apresenta, garantindo a todos o direito as cidades sustentáveis, infraestrutura urbanas e entre elas, o lazer (BRASIL, 2010).

O Projeto de lei, Plano Diretor Municipal, indica também instruções de como deve ser a ordenação do território, controle e distribuição do uso do solo, limitação de zoneamentos, tendo uma maior, ou pelo menos requerida, a participação popular, buscando o desenvolvimento urbano (PMVV, 2017).

Assim, além da existência de espaços livres, deve-se democratizar e incentivar o seu uso. Lima (2015, p. 24) define que esse interesse por espaços de qualidades é um direito do cidadão, afirma que "é necessário refletir sobre os diversos tipos de privação e as possibilidades de distribuição dos bens materiais e culturais por todos. Dessa forma, ter acesso e oportunidades de lazer colocase no mesmo patamar dos anseios e expectativas e direitos a serem conquistados pelo cidadão".

Seguindo o raciocínio, a sensação da segurança advinda da diversidade dos usos e a dinâmica do espaço são determinados pelo traçado da cidade, a distribuição igualitária de espaços livres e suas conexões, bem como, quadras curtas com edificações com uso misto, garantindo assim melhores condições para a diversidade nas cidades (JACOBS, 2007).

Jacobs (2007), em seu livro Morte e vida de grandes cidades, defende que as cidades devem dispor de diversas opções de trajetos, em horários distintos, deve estimular a vigilância natural, através da diversidade no que se diz aos usos e às pessoas que ali transitam, gerando assim o alicerce fundamental para qualidade de vida social e a vitalidade em meios urbanos.

No entanto, o que se verifica, é uma sociedade inserida numa nova configuração do espaço público, remodelando sua interação social, onde, aliadas com o crescimento da violência urbana, desigualdade social e a falta de investimento por parte do poder público desencadeia na segregação do espaço público no cotidiano, antes, lugar de interação social (AMARAL, 2010).

Com a alegação do aumento da violência urbana, os espaços livres de uso público, principalmente os sem qualidade e atrativos, estão sendo cada vez mais esquecidos pela população, segundo Lima (2015, p. 20) o abandono dessas áreas é relacionado a diversos motivos, destacando: " a descaracterização e destruição do patrimônio: os acidentes no trânsito: os roubos: os crimes: os assassinatos, as balas perdidas: o tráfico de drogas: a luta entre gangues, etc."

Em seu livro "Confiança e medo na cidade", Bauman (2009) relata o medo urbano, o desinteresse da população em relação a vida comunitária, cita o termo "mixofobia", que é o medo das pessoas em misturar-se, onde acabam buscando segurança nos ambientes privados em detrimento dos espaços públicos.

Espaços de uso público devem ser pensados a partir de uma percepção mais ampla, pois a violência atinge a todos, mas deve-se refletir diante das necessidades daqueles que lidam cotidianamente com esses fatores, buscando novas formas de atuação nessas áreas. Conforme citado por Lima "a segurança de fato, pressupõe muito mais do que punição e enclausuramento. Pressupõe outra ética de valorização da liberdade, da 
alteridade, da solidariedade e da preservação coletiva da cidade, com a justa distribuição das riquezas e dos saberes" (LIMA, 2015, p. 23).

A conexão entre espaços públicos como agentes para prevenção do crime, tem se tornado um dos meios para mitigar a sensação do medo em escala local, Beato (1998, p. 2) afirma que "a literatura sobre políticas públicas de combate à criminalidade tem enfatizado crescentemente a busca por soluções "locais" e descentralizadas, o que conduz necessariamente à identificação de problemas nos contextos específicos de sua ocorrência".

É possível compreender, portanto, que os espaços livres de uso público influenciam diretamente na qualidade de vida de seus usuários e na vitalidade urbana de uma cidade, a ausência ou a falta de qualidade e atrativos desses espaços podem sugestionar ações indevidas e propiciar a sensação de insegurança.

Regional em estudo (regional 3 - Grande Aribiri) é uma área vulnerável, tanto pela sua trama geográfica, quanto por suas condições sócio econômicas, em contrapartida, são áreas de grandes potencialidades que abrigam áreas livres para uso público, que podem ser melhor exploradas com amplas possibilidades.

\section{METODOLOGIA}

Primeiramente, foi realizada a identificação dos espaços livres para práticas sociais, posteriormente a caracterização urbana e o diagnóstico da área de estudo foram realizados utilizando imagens de satélite, dados geográficos disponibilizados pelo programa Google Earth, Street View e visitas de campo. Após a identificação das áreas, foi desenvolvida uma base cartográfica digital, no programa ArcGIS (versão:10.3.1), de georreferenciamento, formando uma base de dados, abordando diferentes temáticas. Para a elaboração dos mapas de incidências de crimes registrados, foram gerados mapas de densidade com dados fornecidos pela Gerência de Estatística e Análise Criminal (GEAC) do Espírito Santo, dados registrados no período de 01 de janeiro à 31 de dezembro de 2016, para tal efeito utilizou-se de ferramentas que identifica cada crime georreferenciado gerando manchas indicando a maior concentração de incidências. Por fim, foi possível correlacionar os mapas gerados a fim de compreender a relação dos espaços públicos e a ocorrências de crimes.

\section{CARACTERIZAÇÃO URBANA: REGIONAL 3 - GRANDE ARIBIRI}

Vila Velha é o município mais antigo e o segundo mais populoso do Estado do Espírito Santo, com uma população estimada em 476.664 habitantes, sua área territorial é de $209,965 \mathrm{~km}^{2}$ (IBGE, 2010). Limita-se ao norte com o município de Vitória; ao sul com Guarapari; a leste com o oceano Atlântico e a oeste com os municípios de Viana e Cariacica. Para sua melhor organização, Vila Velha possui cinco regiões administrativas, os bairros desse estudo ficam na Regional 3 - Grande Aribiri. Segundo a Lei Municipal $n^{\circ} 4707 / 2008$ os bairros que compõem a Regional 3 são: Argolas; Aribiri; Ataíde; Cavalieri; Chácara do Conde; Dom João Batista; Garoto; Ilha da Conceição; Ilha das Flores; Paul; Pedra dos Búzios; Primeiro de Maio; Sagrada Família; Santa Rita; Vila Batista; Vila Garrido e Zumbi dos Palmares, conforme figura 1 (Vila Velha, 2008). 


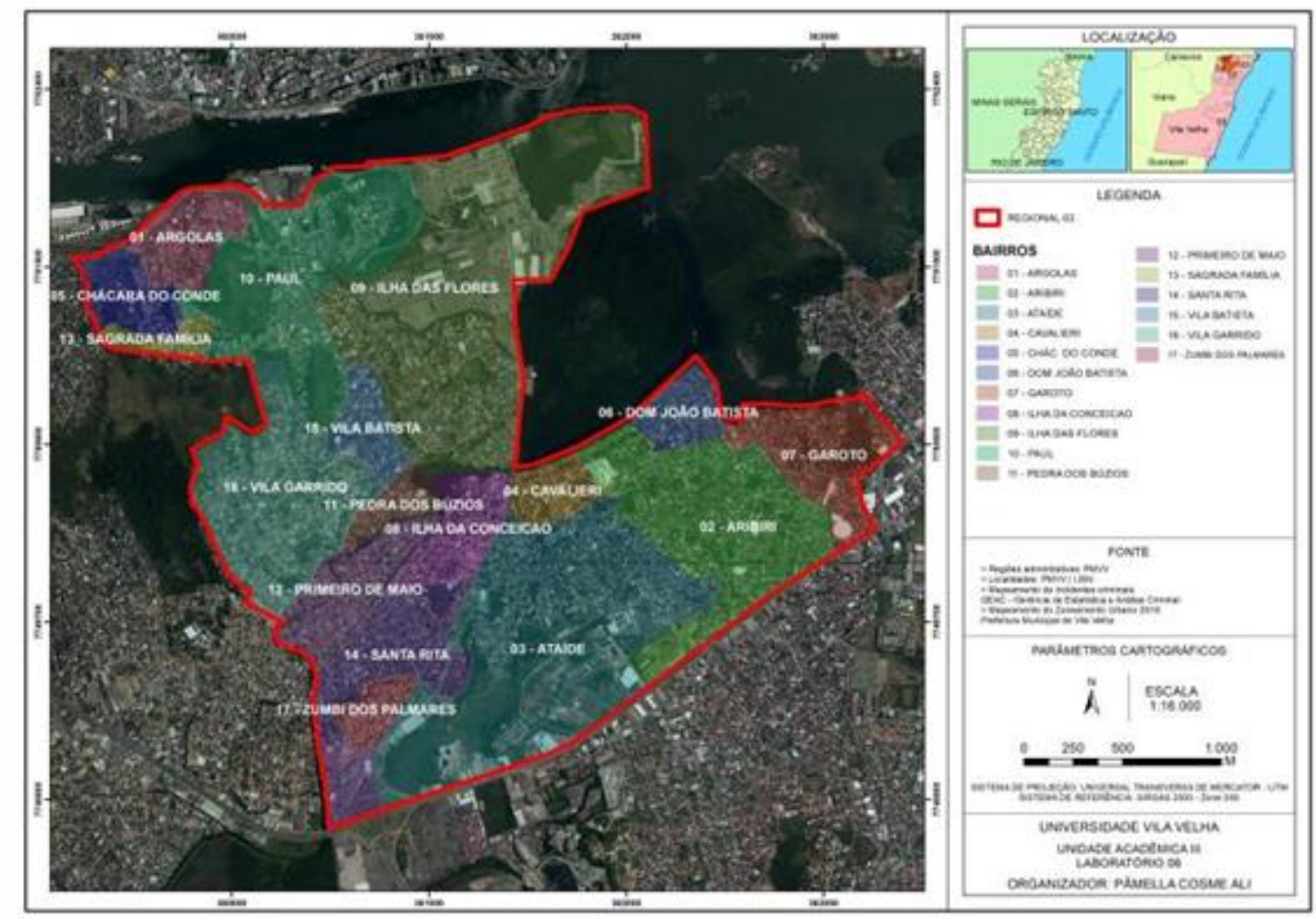

Figura 1 - Localização dos Bairros

Fonte: Acervo da pesquisa (2018)

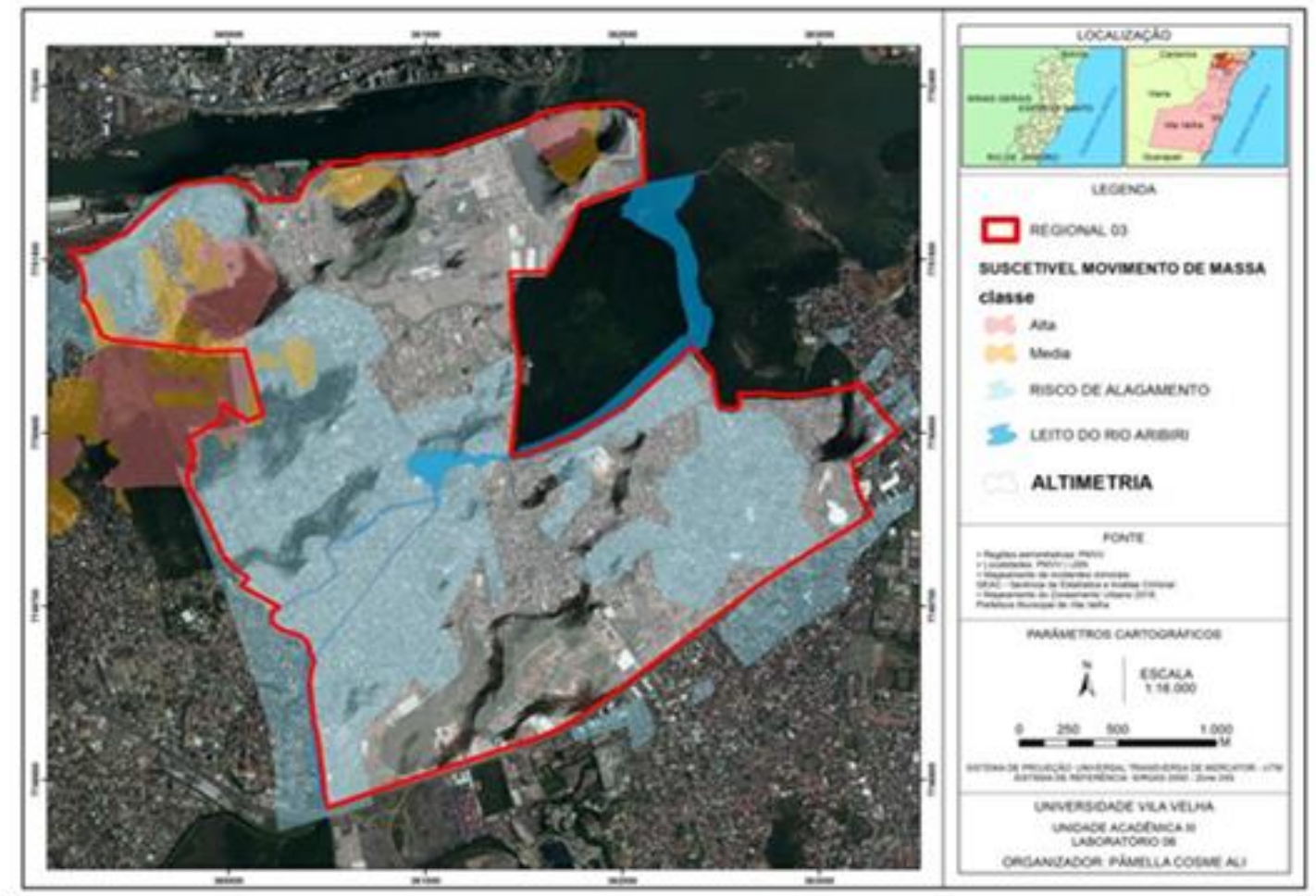

Figura 2 - Identificação das Áreas de Risco, Regional 3, Vila Velha - ES

Fonte: Acervo da pesquisa, 2017

A Cidade de Vila Velha sofreu um grande e desordenado crescimento populacional na década de 50, o que foi intensificado com a crise do café, aumentando a ida das pessoas para a cidade, ocasionando a ocupação de áreas alagadas, com alta declividade, áreas de proteção ambiental, como é 
possível observar na figura 2, que demarca as áreas de risco de alagamentos e suscetíveis deslizamentos de terra presentes na Regional 3. (MOVIVE; VERDE VIVA, 2002).

Outro acontecimento que ocorreu no perímetro de Vila Velha, de suma importância para compreender o desenvolvimento da Regional 3, foi o crescimento ao longo das margens da Bacia Hidrográfica de Ariri (Rio Aribiri), desde o mangue Espera da Maré até o Parque da Manteigueira. Inicialmente esse rio era fonte de alimentos, trabalho e transporte para essa população, mas hoje é possível verificar a existência de ocupações irregulares, as margens dos. Observa-se também, a falta de saneamento básico nos bairros da regional, ocasionando polvição do rio, com exibição do esgoto a céu aberto, como é possível conferir na figura 3, margens do Canal de Aribiri (MOVIVE E VERDE VIVA, 2002).

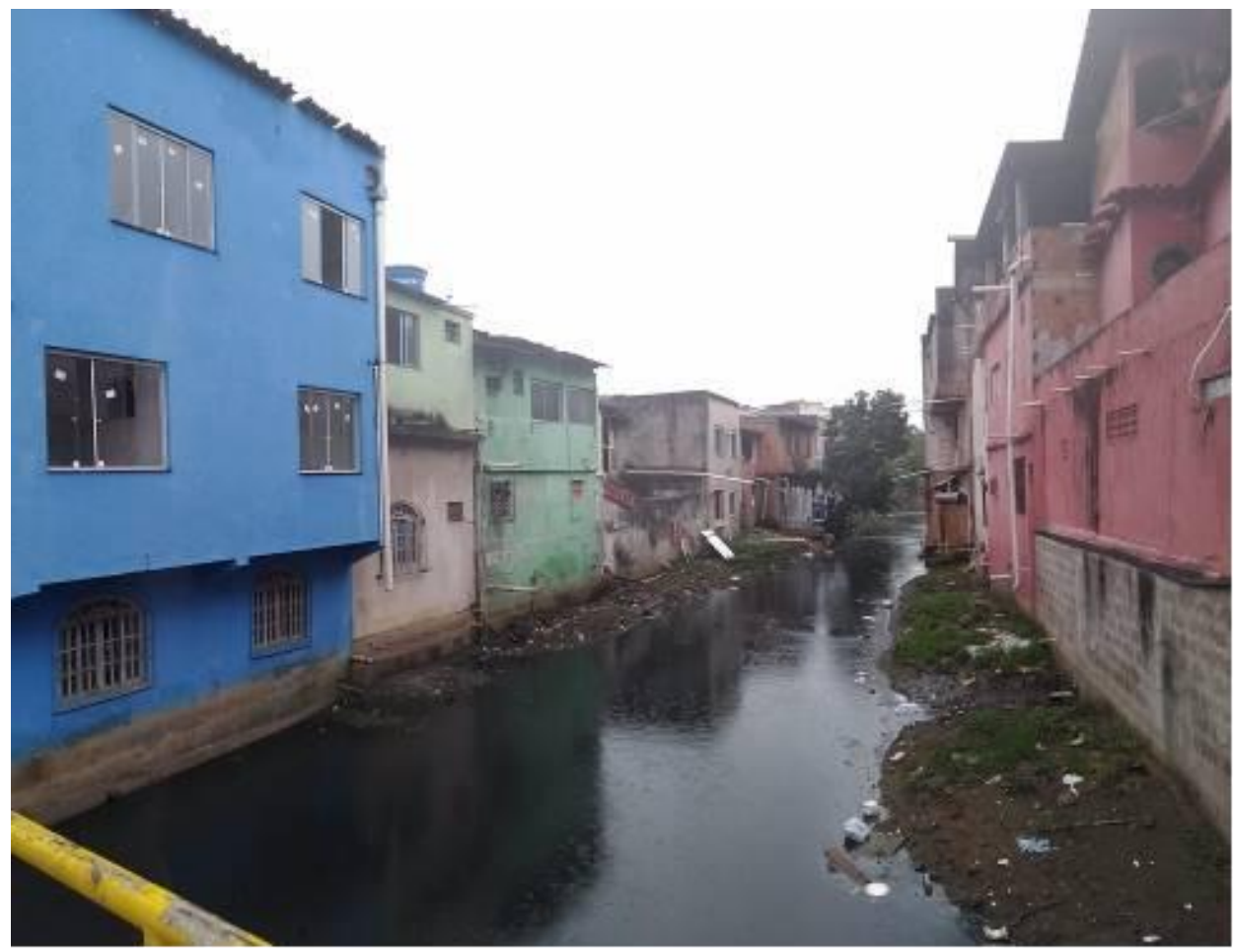

Figura 3 - Canal do rio Aribiri - Vila Velha - ES

Fonte: Acervo da pesquisa

É de suma importância compreender como se consolidou a Regional Grande Aribiri. O entendimento da consolidação urbana da Regional auxiliou na interpretação da ocupação em áreas de risco e a falta de espaços livres de uso público.

\section{A CARACTERIZAÇÃO DAS ÁREAS LIVRES DE USO PÚBLICO E A INCIDÊNCIA DE CRIMES NA REGIONAL 3}

Dentro do cenário urbano da Regional 3 foi possível identificar o total de 9 (nove) praças, que estão localizadas nos bairros Argolas, Aribiri, Ataíde, llha da Conceição, Paul, Santa Rita e Vila Garrido, sendo que 3 (três) delas, estão situadas no bairro Aribiri. A Figura 4 apresenta os espaços livres de uso público para práticas sociais da Regional 3 e o raio de abrangência de 300 metros de cada uma delas, considerado este raio, uma distância aceitável, ao permitir o deslocamento a pé, em torno de 3 a 4 minutos, até a praça. 


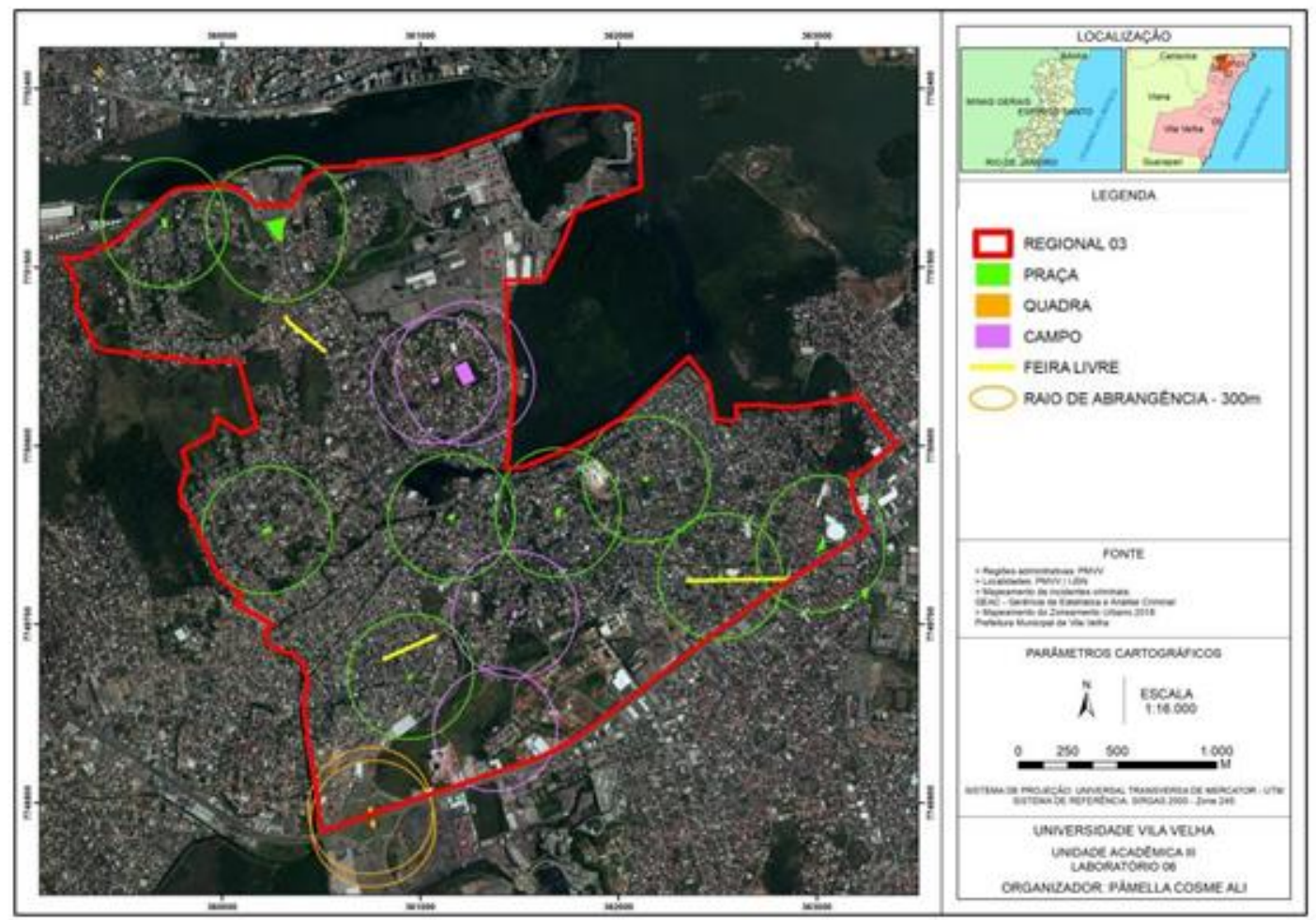

Figura 4 - Mapeamento das áreas livres de uso público destinada a práticas sociais Fonte: Acervo da pesquisa

Através do mapeamento identificou-se, em toda a Regional 3, apenas 9 praças, 4 campos de futebol e 2 quadras poliesportivas, o que corresponde que somente $30 \%$ da população, residente na Regional estudada, possui, em um raio de 300 metros de abrangência, acesso as praças. Percebe-se, desta forma, uma má distribuição dos espaços livres para práticas sociais entre os bairros da Regional.

Constata-se neste estudo que 11 bairros dessa Regional (Bairros Cavalieri, Chácara do Conde, Dom João Batista, Garoto, llha das Flores, Pedra dos Búzios, Primeiro de Maio, Sagrada Família, Vila Batista, e Zumbi dos Palmares) não possuem espaços livres para práticas sociais consolidado.

Entre os espaços livres de uso público, presentes na Regional 3, deu-se foco nas análises e caracterização das praças, que são áreas voltadas para lazer, convívio social, atividades esportivas, recreação infantil e lazer para idosos. O objetivo desta análise foi verificar a qualidade e manutenção dos espaços existentes.

Neste sentido, para qualificar as áreas livres de uso público, foi usado como suporte o Manual de Espaços Públicos (PROGRAMA SOLUÇÕES PARA CIDADES, 2013), para definir as condições de um espaço público, a fim de identificar suas deficiências, carências. Foram realizadas visitas de campo para identificar esses elementos e realizado um checklist, figura $5 \mathrm{com}$ indicadores relacionados a infraestrutura, atrativos e vivências. 


\begin{tabular}{|c|c|c|c|c|c|c|c|c|c|c|c|c|}
\hline \multicolumn{13}{|c|}{ CMECKUIST } \\
\hline BAIRRO & ID DA PRACA & $\begin{array}{l}\text { anthe } \\
\left\langle m^{\prime}\right\rangle\end{array}$ & ACEss studade & HeMnuacia & 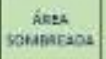 & $\begin{array}{l}\text { zespacodo: } \\
\text { aescanso }\end{array}$ & $\begin{array}{l}\text { OUADRa! } \\
\text { CQMAPO: }\end{array}$ & 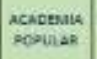 & wern & $\begin{array}{c}\text { Asen } \\
\text { meaneravil }\end{array}$ & 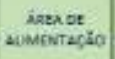 & Denendus \\
\hline ARGOLC5 & Semtrname & 1209,06 & 0 & 0 & 0 & 0 & 0 & 0 & 0 & 0 & 0 & 0 \\
\hline \multirow{3}{*}{ AB:aiai } & Press Aribari & 538,95 & 0 & 0 & 0 & 0 & 0 & 0 & 0 & 0 & 0 & 9 \\
\hline & lowi Veress & nia, ,in & $\theta$ & 0 & 0 & 0 & 2 & 0 & 0 & 0 & 0 & 0 \\
\hline & Conjunto Bercelios & 1586,07 & 0 & 0 & 0 & 0 & 0 & 0 & 0 & 0 & 0 & 0 \\
\hline RTNide & Proso do Amiesde & 1051,49 & 9 & 0 & 0 & 0 & 0 & 0 & 0 & 0 & 0 & 0 \\
\hline EHA DU COHCEICPOO & semnome & 771,33 & $\omega$ & 0 & $\boldsymbol{\varphi}$ & 0 & 0 & $\omega$ & $\omega$ & 9 & 9 & 0 \\
\hline FAUL & Frosinha do Paul & 6003,3 & 0 & 0 & 0 & 0 & 0 & 0 & 0 & 0 & 0 & 0 \\
\hline SAN12aira & twm nome & 1229,1 & 0 & 0 & 2 & 0 & 0 & 0 & 0 & 3 & 0 & 0 \\
\hline VIA GARPDOO & Remon Mortiner & 1275,5 & 0 & 0 & 0 & 0 & $\theta$ & 0 & 0 & 0 & 0 & 0 \\
\hline
\end{tabular}

Figura 5 - Checklist análise das praças

Fonte: Acervo da pesquisa

Outro dado explorado foram as incidências de crimes ocorridos nessa Regional. Os bairros inseridos nesse contexto, em sua maioria, estão em áreas vulneráveis, muitas vezes dominados pelo tráfico de drogas, guerras entre gangues

A falta de segurança ou a sensação de insegurança, deve-se, na maioria dos casos, pela escassez de manutenção e qualidade nos espaços públicos. Além disso, nem todos possuem atrativos que propiciam uso e que incentivem a permanência nas praças, como área para recreação infantil, quadras ou campos, iluminação adequada, policiamento, academias populares, atividades que dinamizem o uso tanto diurno quanto noturno nas praças.

No mapa apresentado na figura 6 é possível observar, em uma escala de gradação (vermelho para maior incidência e azul para menor incidência), a mancha com a incidência de crimes de roubos e furtos registrados, podendo ser esses crimes em via pública ou em diversos tipos estabelecimentos.
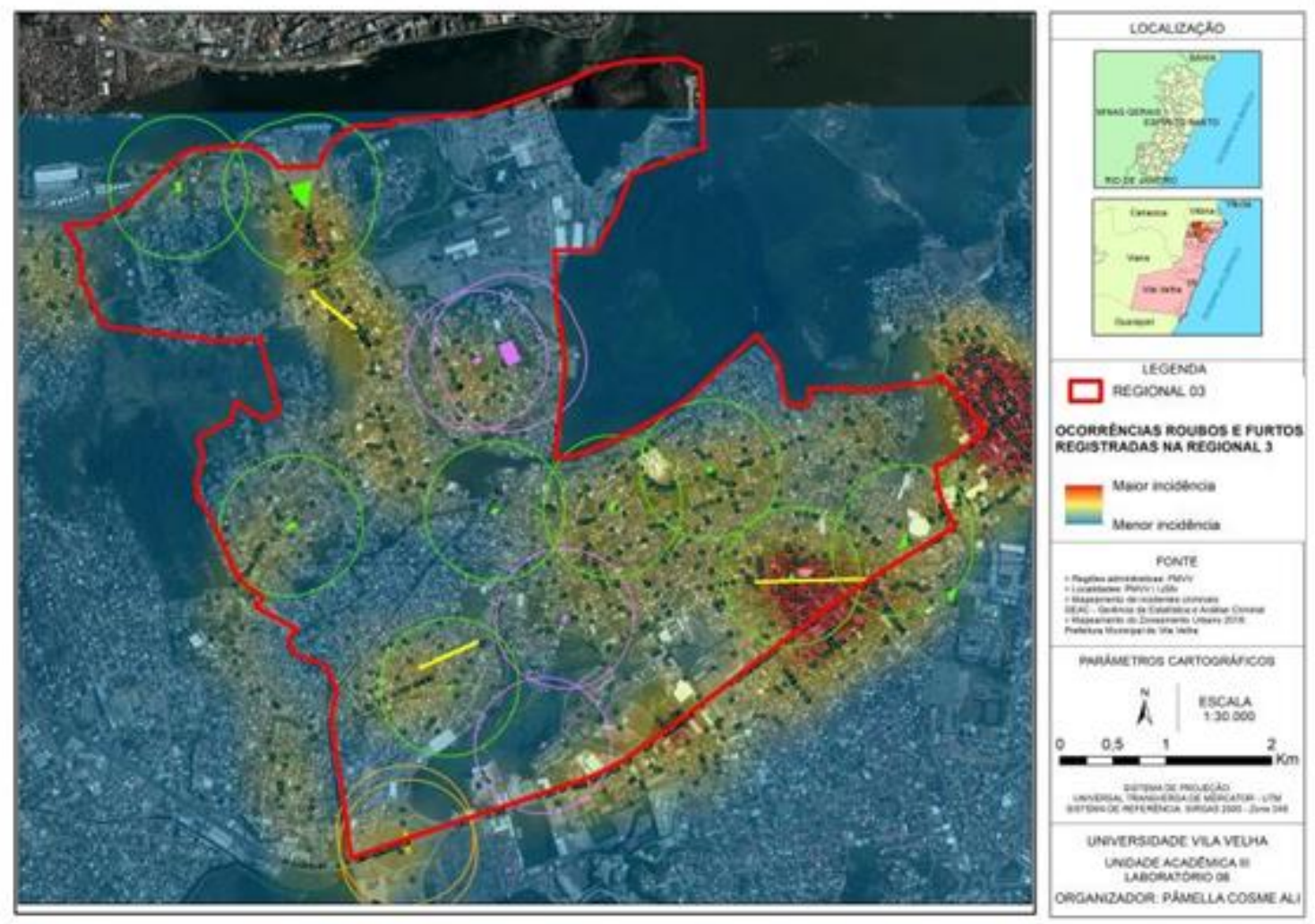

Figura 6 - Ocorrências de roubos e furtos - Regional 3, Vila Velha - ES

Fonte: Acervo da pesquisa 
Percebe-se que as manchas vermelhas, que representam a maior quantidade de ocorrências registradas, apresentam-se em maior evidência em áreas comerciais, o que é comum, já que também estão sendo analisados os registros de crimes nesses estabelecimentos.

Foram registrados o total de 1311 ocorrências de roubos e furtos na Regional 3, foi possível observar a concentração de crimes próximo a pracinha de Paul e Pracinha de Aribiri, áreas muito comerciais.

Quando se trata de dados de tráfico, posse/uso e apreensão de entorpecentes a mancha vermelha, que ilustra as maiores incidências muda de lugar, é possível observar na figura 7, que as ocorrências se concentram principalmente nos bairros Santa Rita, Primeiro de Maio e llha da Conceição.
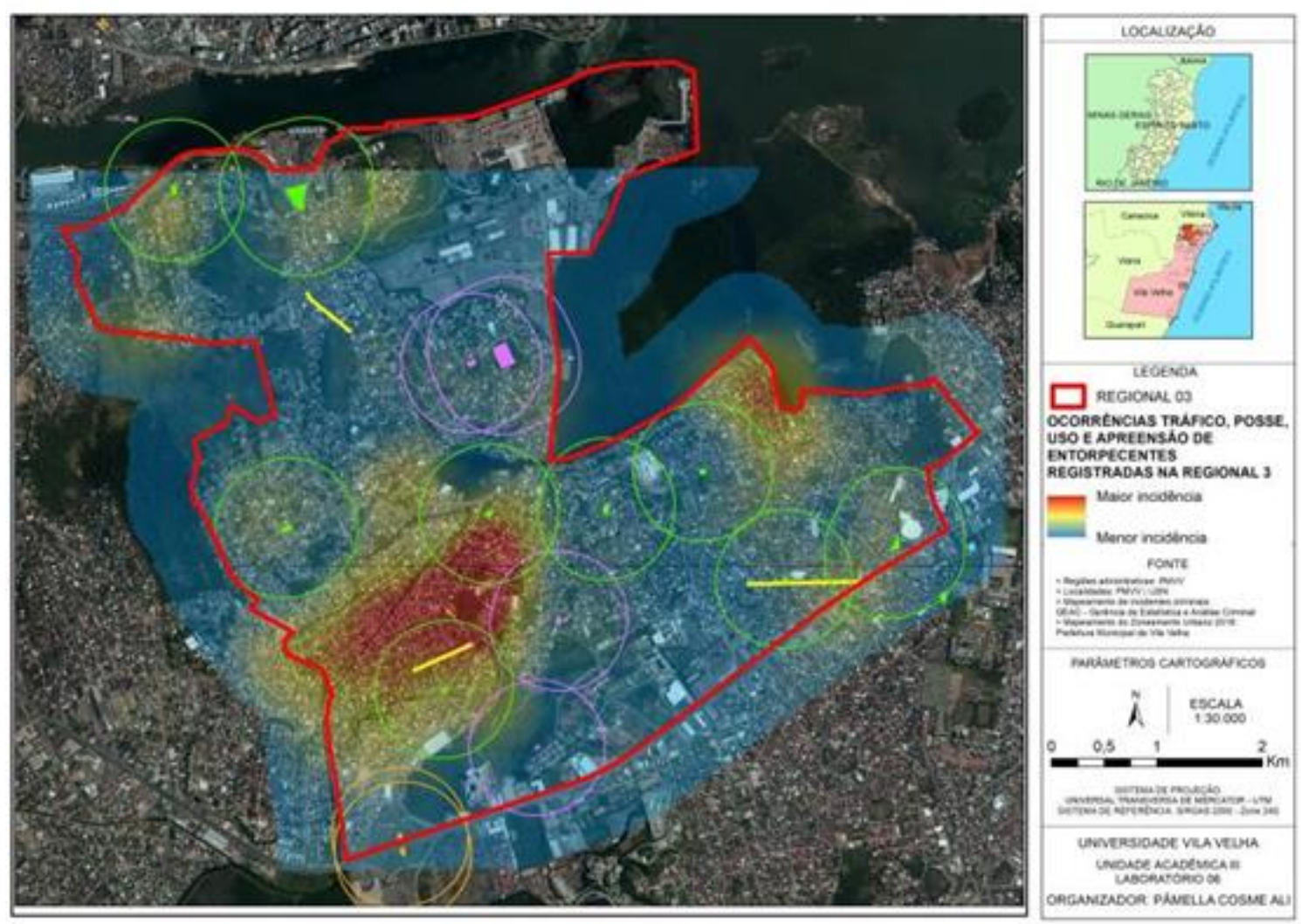

Figura 7 - Ocorrências de tráfico, posse/uso e apreensão de entorpecentes Regional 3, Vila Velha - ES

Fonte: Acervo da pesquisa

Segundo os dados disponibilizados foram registradas 309 ocorrências desse tipo de crime

Quanto as ocorrências de homicídios e tentativas de homicídios, conforme figura 8, as manchas se espalham na Regional, ficam mais evidentes e concentradas nos bairros Santa Rita, Zumbi dos Palmares, Primeiro de Maio, llha da Conceição e parte de Pedra dos Búzios.

Todos os bairros citados com alto número de registro de ocorrências violentas, são bairros com um longo histórico de disputa pelo controle do tráfico de drogas, provocando uma verdadeira guerra na região. 
Nota-se que a concentração das manchas é muito parecida entre os crimes de tráfico, posse/uso e apreensão de entorpecentes com as ocorrências de homicídios e tentativas de homicídios.

Segundo dados disponibilizados pelo Instituto Jones dos Santos Neves, dentre os 20 bairros do Município de Vila Velha com maior influência do tráfico de drogas doze concentram-se nos bairros da Regional 3, sendo eles (em ordem de maior influência) Vila Garrido, Argolas, Vila Batista, Pedra dos Búzios, Ilha das Flores, Dom João Batista, Aribiri, Ilha da Conceição, Ataíde, Zumbi dos Palmares, Santa Rita e Primeiro de Maio (IJSN, 2016)
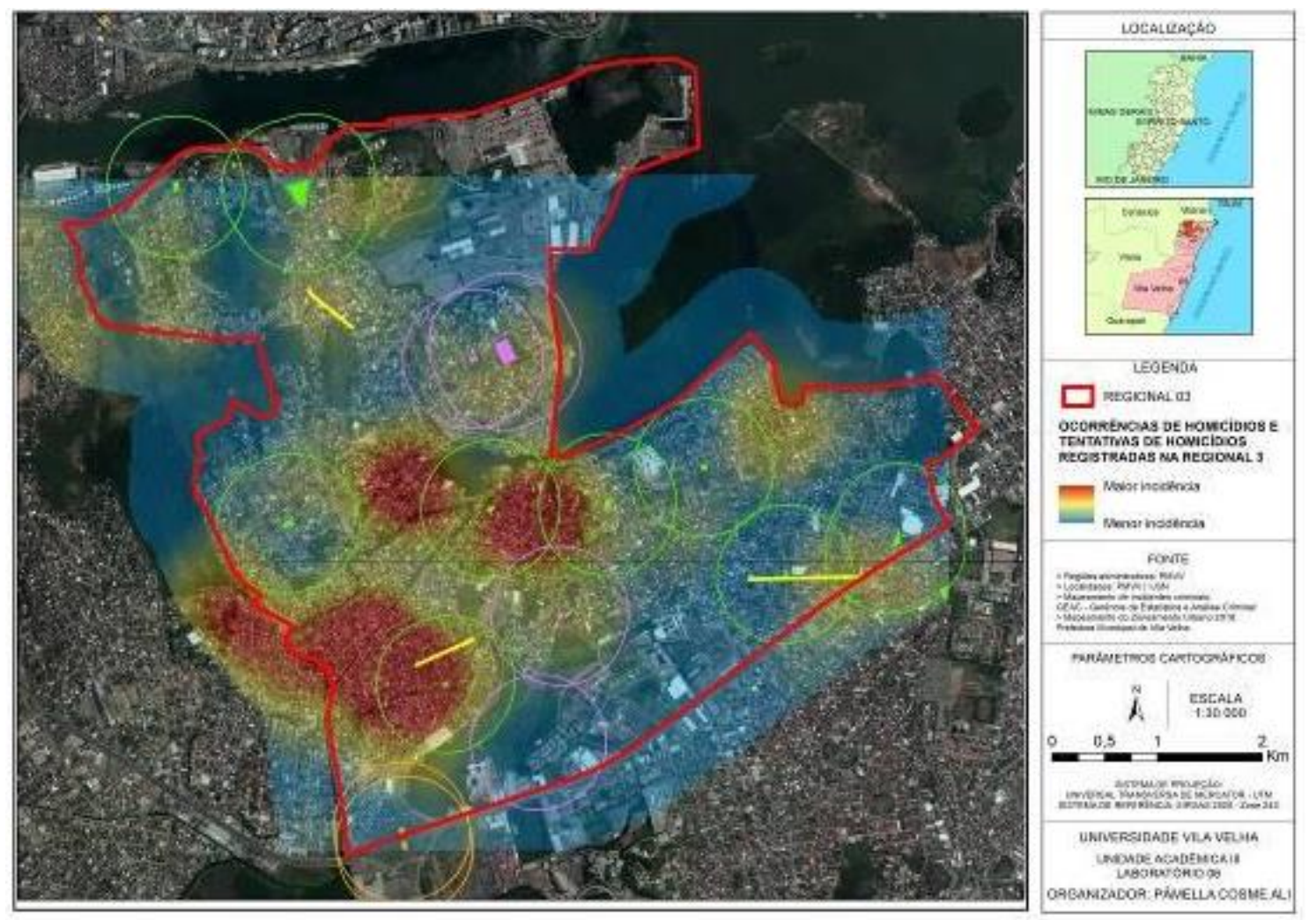

Figura 8 - Ocorrências de homicídios e tentativas de homicídios - Regional 3, Vila Velha - ES

Fonte: Acervo da pesquisa

Em se tratar dos dados já analisados e demonstrados como os de roubos e furtos, tráfico, posse/uso e apreensão de entorpecentes e as ocorrências de homicídios e tentativas de homicídios os números de ocorrências são altos, mas quando se acrescenta esses dados com outros crimes violentos como lesão corporal, disparo e posse de arma de fogo o contexto muda e os números aumentam, como é possível observar no quadro abaixo.

Essa análise sugere também que nessas áreas de maior incidências de crimes não há espaços livres de uso público, o que poderia contribuir para a falta de pertencimento local, a ocupação e a dinâmica do espaço, fatores que naturalmente proporcionariam segurança e vigilância, evitando ou minimizando a ocorrência de homicídios. 
Quadro 1 - Total de Registros de ocorrências

\begin{tabular}{|l|c|}
\hline \multicolumn{1}{|c|}{ OCORRÊNCIAS } & 2016 \\
\hline Roubos e furtos & 1311 \\
\hline $\begin{array}{l}\text { Tráfico, posse/uso e apreensão de } \\
\text { entorpecentes }\end{array}$ & 309 \\
\hline Homicídios e tentativas de homicídios & 109 \\
\hline Todos as incidências & 2092 \\
\hline
\end{tabular}

Fonte: acervo da pesquisa

A exemplo do uso de espaços livres como ferramenta para a prevenção do crime e geração de qualidade de vida, a Cidade de Medellín tornou-se modelo em eficiência, mostrando o poder de transformação e mobilização de uma cidade quando se tem um objetivo em comum, trabalhando no fortalecimento da comunidade e principalmente na qualidade dos espaços públicos, levando cultura e qualidade de vida a população. O ponto de partida do projeto de Medellín foi o uso do espaço público como norteador dos projetos, a participação popular foi fundamental, pois a atuação da comunidade local, desencadeou no processo de pertencimento e potencialização o uso e conservação do espaço público. (MUNIZ, 2018)

São enormes os desafios com relação aos conflitos no campo da violência urbana e a sensação de insegurança, estas influenciam nas relações e comportamentos sociais, delimitando e bloqueando tudo aquilo que não é aceito socialmente, porém existem diversas experiências, internacionais e nacionais, que comprovam que é possível mitigar esses índices com espaços públicos de qualidade, integração e participação ativa entre população e poder público, e, principalmente, planejamento territorial, tratar cada região com suas necessidades.

\section{CONSIDERAÇÕES FINAIS}

A região em estudo é uma área em constante transformação e desenvolvimento, a população, por sua vez, ocupa áreas já com alto adensamento, continuando um crescimento desordenado, ocupando áreas alagadas, suprimindo áreas verdes, afetando diretamente na qualidade de vida das pessoas.

Os espaços livres de uso público, como demonstrado, não atendem os bairros da regional de forma homogênea, sugerindo a desigualdade na distribuição dos investimentos e um alto índice de crimes violentos ocorrendo justamente em áreas com ausência desses espaços.

Muitas vezes a falta de manutenção, infraestrutura e atrativos ocasionam espaços ociosos e sem uso, gerando a insegurança nessas áreas.

Um ponto importante de se destacar é que os bairros dessa Regional possuem muito potencial para se trabalhar em pequenas escalas, são muitas escadarias para serem transformadas, ruas pequenas, vias que podem ter 0 pedestre como prioridade, valorizando o comércio e a comunidade local, muitas áreas íngremes que são áreas residuais da malha urbana já 
consolidada, todo o canal do Rio Aribiri, que hoje está completamente abandonando gerando transtorno e prejuízo para as comunidades próximas

Os estudos gerados, podem ser fomento para futuras intervenções, para criação e transformação de novos espaços livres de público para a Regional, visando sempre melhorar a qualidade de vida da população e a qualidade do espaço urbano.

\section{REFERÊNCIAS}

AMARAL, Layne. O imaginário do medo: violência urbana e segregação espacial na cidade do rio de janeiro. Contemporânea, v. 8, n. 1.

2010. Disponível em:

<http://wWw.contemporanea.verj.br/pdf/ed_14/contemporanea_n14_04_ama ral.pdf>.Acesso em: out. 2018.

BARGOS, D. C.; MATIAS, L. F.. Áreas verdes urbanas: um estudo de revisão e proposta conceitual. Soc. bras. de arborização urbana, São Paulo, v. 6, n. 3, p. 172-188, 2011..

BAUMAN, Zygmunt. Confiança e medo na cidade. Rio de Janeiro: J. Zahar, 2009

BEATO F., Claudio C. Determinantes da criminalidade em Minas Gerais. Rev. bras. Ci. Soc. [conectados]. 1998, vol.13, n.37, pp. 74-87. ISSN 01026909. http://dx.doi.org/10.1590/S0102-69091998000200004

GEHL, Jan. Cidade para Pessoas. São Paulo: Perspectiva. 2014.

IBGE. Instituto Brasileiro de Geografia e Estatística. CENSO DEMOGRÁFICO 2010. Características da população e dos domicílios: resultados do universo. Rio de Janeiro: IBGE, 2010.

IJSN. As Leis do Tráfico. A Gazeta, VITÓRIA - ES, p. 12-15, 4 dez. 2016. Disponível em:

http://www.ijsn.es.gov.br/ConteudoDigital/20170105_aj25425_drogas_trafico.p df.

JACOBS, J. Morte e vida de grandes cidades. São Paulo: Martins Fontes, 2007.

LIMA, Dália Maria Maia Cavalcanti de. A VIOLÊNCIA URBANA E A SENSAÇÃO

DE INSEGURANÇA NOS ESPAÇOS PÚBLICOS DE LAZER DAS CIDADES Disponível em:

<http://www2.ifrn.edu.br/ojs/index.php/geoconexoes/article/view/3692/1202>. Acesso em: nov. 2018.

LOBODA, C. R.; ANGELIS, B. L. D. Áreas verdes públicas urbanas: conceitos, usos e funções. Ambiência. Revista do centro de ciências agrárias e ambientais, Guarapuava, pr , v. 1, n. 1, p. 125139,jan./jun. 2005.

LYNCH, Kevin. Image of the city. Cambridge: MIT Press, 1960

Maricato, Ermínia. (2000). Urbanismo na periferia do mundo globalizado:

metrópoles brasileiras. São Paulo em Perspectiva, 14(4), 21 -

33. https://dx.doi.org/10.1590/S0102-88392000000400004

MENDONÇA, E. M. S. Apropriações do Espaço Público: Alguns Conceitos. Estudos e Pesquisas em Psicologia, Rio de Janeiro, v. 7, $n^{\circ}$ 2, dez/2007. 
Disponível em: <http://pepsic.bvsalud. org/scielo.php?pid=\$180842812007000200013\&script=sci_arttext>

MOVIVE. VERDEVIDA. Diagnóstico sócio-econômico e ambiental região do Aribiri. Diagnóstico sócio- econômico e urbanistico - Vila velha - ES , v. 1, dez. 2002.

MUNIZ, Isabella Batalha. A participação cidadã e o espaço público como agentes de transformação: o caso de Medellín. 2018. Disponível em:<https://cidadesepassagens.com.br/participacao-cidada-e-o-espacopublico-como-agentes-de-transformacao-o-caso-de-medellin/>.

NOVO PDM VILA VELHA. Mapas. Disponível em: <http://pdm.vilavelha.es.gov.br/mapas/>. Acesso em: Dez. 2016.

NYGAARD, D. P. Espaço Da Cidade, Segurança Urbana e Participação Social. Porto Alegre: Livraria do Arquiteto, 2010. Parque Sitiê. Disponível em: < http://www.parquesitie.org/> Acesso em: Jan. 2017.

SÁ CARNEIRO A.R. E MESQUISA L.B. Espaços livres do Recife. Universidade Federal de Pernanbuco, 2000.

SABOYA, R. T. de. "Fatores morfológicos da vitalidade urbana - Parte 1: Densidade de usos e pessoas. Publicado em 18 Nov 2016. ArchDaily 59 Brasil. Acessado em 04 de Junho de 2018. http://www.archdaily.com.br/br/798436/fatores-morfologicos-da-vitalidadeurbana-nilparte-1-densidadede-usos-e-pessoas-renato-t-de-saboya Schlee, M., Nunes, M. J., Rego, A., Rheingantz, P., Dias, M. Ângela, \& Tangari, V. (2009). Sistema de Espaços Livres nas Cidades Brasileiras - Um Debate conceitual. Paisagem E Ambiente, https://doi.org/10.11606/issn.23595361.v0i26p225-247 - http://www.revistas.usp.br/paam/article/view/77358 